\title{
Validity and Reliability of the Spanish Version of Fear of COVID-19 Scale in Colombian Physicians
}

\author{
María Fernanda Mercado-Lara ${ }^{1}$ (D) - Adalberto Campo-Arias ${ }^{2}$ (D) \\ Álvaro Monterrosa-Castro ${ }^{1}$
}

Accepted: 11 November 2020/ Published online: 4 January 2021

C Springer Science+Business Media, LLC, part of Springer Nature 2021

\begin{abstract}
The Fear COVID-19 Scale (FCV-19S) is a tool that assesses fears related to COVID-19. The objective was to know the validity and reliability of the FCV-19S in Colombian physicians. Five hundred thirty-one physicians aged between 21 and 69 years participated $(\mathrm{M}=30.0, \mathrm{SD}=9.4)$. Internal consistency was estimated with Kuder-Richardson and McDonald's omega coefficients. The one-dimensional structure was corroborated with confirmatory factor analysis and goodness of fit coefficients. The FCV-19S showed Kuder-Richardson's coefficient of 0.16 and McDonald's omega of 0.42. The five-item version (FCV-19S-5), without items 3 and 7, showed Kuder-Richardson's coefficient of 0.67 and McDonald's omega of 0.68. In conclusion, the FCV-19S presented a poor psychometric performance in Colombian doctors, and the FCV-19S-5 showed acceptable internal consistency and dimensionality.
\end{abstract}

Keywords Fear $\cdot$ COVID-19 $\cdot$ Physicians $\cdot$ Factor analysis $\cdot$ Validation studies

Coronavirus disease 2019 (COVID-19) was first identified in December 2019, in Wuhan, China (World Health Organization 2020). On January 30, 2020, the World Health Organization (WHO) declared COVID-19 as a public health emergency of international concern. In

Adalberto Campo-Arias

acampoa@unimagdalena.edu.co

María Fernanda Mercado-Lara

mmercadol1@unicartagena.edu.co

Álvaro Monterrosa-Castro

amonterrosac@unicartagena.edu.co; alvaromonterrosa@gmail.com

1 Research Group of Women's Health, Faculty of Medicine, University of Cartagena, Cartagena, Colombia

2 Medicine Program, Faculty of Health Sciences, University of Magdalena, Carrera 32 No. 22-08, Bloque 8, Gorgona, Segundo piso, oficina Psicología de la Salud y Psiquiatría, Santa Marta 470004, Colombia 
Colombia, as of September 21, 2020, there have been 770,435 confirmed cases and 24,397 reported deaths. However, the relatively early measures taken to reduce the spread of the epidemic, for example, the significant restriction of mobility or physical distancing (Colombian National Health Institute 2020), fear in the population persisted due to mistrust in the health system and state authorities (Pedrozo-Pupo et al. 2020). Fear can motivate people to adopt health recommendations and partially reduce the stress associated with an unfavourable situation. (Nabi and Myrick 2019).

The daily increase in the number of cases, the increase in the workload, the lack of personal protective equipment, the general coverage of the media and the lack of specific treatment contributed to the psychological distress in doctors (Lai et al. 2020).

Fear has been defined as a negatively valenced emotion, with a high level of arousal (Witte and Allen 2000). High levels of fear of getting COVID-19 are reported in the general population and health personnel (Lin 2020; Knipe et al. 2020; Lu et al. 2020). Fear is an emotional response to impending threats (Van Bavel et al. 2020), which leads to irrational thoughts (Ahorsu et al. 2020), and even favours the recurrence of pre-existing mental disorders (Colizzi et al. 2020). Psychological manifestations reflect the importance of assessing fear of COVID-19 in different populations (Tzur Bitan et al. 2020).

Two scales have been designed to assess fears related to COVID-19. The COVID-19 Peritraumatic Distress Index (CPDI) is a 24-item questionnaire that explores anxiety, depression, specific phobias, physical symptoms and loss of social function in the last week related to COVID-19 (Qiu et al. 2020). On the other hand, the Fear COVID-19 Scale (FCV-19S) is a specific seven-item tool to assess manifestations of anxiety associated with fear of COVID-19 (Ahorsu et al. 2020).

For this study, the FCV-19S was chosen to explore psychometric performance because it is a short, self-directed, one-dimensional scale, and specific to assess fear of COVID-19. Additionally, the original version and versions in other languages have shown robust psychometric properties. In Iran, the FCV-19S showed a one-dimensional structure, with an acceptable corrected item-total correlation, high factor loads, and excellent internal consistency $(\alpha=0.82)$ (Ahorsu et al. 2020). In Turkey, the one-dimensional structure was corroborated, with factor loads greater than 0.500 and high internal consistency $(\alpha=0.86$ ) (Haktanir et al. 2020). In Bangladesh, in participants older than 10 years, a one-dimensional structure was again observed for the FCV-19S, with adequate goodness-of-fit coefficients, and excellent internal consistency ( $\alpha=0.87$ ) (Sakib et al. 2020). In Russia and Belarus, among university students, students, teachers and administrative staff, a high internal consistency was documented $(\alpha=0.81)$ (Reznik et al. 2020). Furthermore, finally, in Italy, in adults between 18 and 76 years, it was observed that the FVC-19S had good correlations between each item and the score, high factor loadings and high internal consistency $(\alpha=0.87)$ (Soraci et al. 2020).

The performance of the FCV-19S in Spanish is unknown; a language is spoken by approximately 570 million inhabitants and is the official language in more than 20 countries in Africa, America and Europe (Instituto Cervantes 2018). Spanish is a language with some singular features of paramount importance when translating and adapting scales from other languages, usually from English. For example, questions in negative sentences induce confusion (Barnette 2000; Weems et al. 2003). It is necessary to know the performance of the FCV$19 \mathrm{~S}$ in different languages and populations since the performance of these measurement instruments can vary significantly according to the characteristics of the participants and, consequently, impair the validity and reliability of the measurement (Keszei et al. 2010; Sánchez and Echeverry 2004). 
The objective was to know the validity and reliability of the FCV-19S in a non-probabilistic sample of Colombian physicians.

\section{Method}

\section{Design and Ethical Considerations}

A validation study was designed within the DISEU project (Psychosocial Dynamics in University Students-COVID-19 arm). This project was reviewed and approved by an institutional research ethics committee (University of Cartagena, Colombia). Physicians participated anonymously and voluntarily, and gave informed consent online. The principles for research with the participation of humans were followed as presented in the Declaration of Helsinki of the World Medical Association (World Medical Association 2018) and Resolution 8340 of 1993 of the Ministry of Health of Colombia (Ministry of Health of Colombia, 1993).

\section{Participants}

A sample was taken for convenience. The participation of at least 400 participants was expected to have an acceptable random error (MacCallum et al. 1999). A group of 531 medical professionals aged between 21 and 69 years $(\mathrm{M}=30.0, \mathrm{SD}=9.4)$. More demographic information is presented in Table 1. Participants should be graduate professionals and work in healthcare activities, in- or out-patient, at any level of complexity, in public or private institutions, and their patients have consulted for any affection or health condition.

\section{Instrument}

The FCV-19S is an instrument of seven that explores anxiety symptoms associated with fear of COVID-19. The original version offers five response options that are rated from one to five, from strongly disagree to strongly agree (Ahorsu et al. 2020). However, for this exploration, a

Table 1 Description of participants

\begin{tabular}{llc}
\hline Variable & Number & Percent \\
\hline Age (years) & & \\
$21-29$ & 249 & 46.9 \\
$30-44$ & 217 & 40.9 \\
45 or more & 65 & 12.2 \\
Gender & & \\
Female & 316 & 59.5 \\
Male & 215 & 40.5 \\
City of working & & \\
Large & 389 & 73.3 \\
Small & 142 & 26.6 \\
Region & & \\
Caribbean & 294 & 55.4 \\
Andean & 220 & 41.4 \\
Other & 17 & 3.2 \\
\hline
\end{tabular}


yes or no response pattern was preferred, simpler to answer in Spanish and to qualify. A point was assigned to each affirmative answer. Dichotomous response patterns vary little in the performance of scales when measuring solid constructs (López 2005). The items are presented in English and Spanish below:

1. I am most afraid of coronavirus-19 (Tengo mucho miedo del coronavirus-19).

2. It makes me uncomfortable to think about coronavirus-19 (Me incomoda pensar en el coronavirus-19).

3. My hands become clammy when I think of coronavirus-19 (Mis manos se ponen húmedas cuando pienso en el coronavirus-19).

4. I am afraid of losing my life because of coronavirus-19 (Temo morir por el coronavirus-19).

5. When watching news and stories about coronavirus-19 on social media, I become nervous or anxious (Cuando veo noticias e historias sobre el coronavirus-19 en las redes sociales, me pongo nervioso o ansioso).

6. I cannot sleep because I am worrying about getting coronavirus-19 (Es dificil dormir porque me preocupa contraer el coronavirus-19).

7. My heart races or palpitate when I think about getting coronavirus-19 (Mi corazón se acelera o me dan palpitaciones cuando pienso en contraer el coronavirus-19).

\section{Procedure}

Previously, a translation process from English to Spanish was carried out. Two independent bilingual professionals handled the process. There were minor divergences that were resolved by consensus (Guimaraes et al. 2017). Denial was avoided in the sixth item given the problems that these usually generate in Spanish (Barnette 2000; Weems et al. 2003). The Spanish version was translated back into English by a third person. The linguistic equivalence seemed excellent between the original English version and the version that was obtained from the Spanish version.

A daily call was made through social networks (Instagram, Facebook, Linkedin) and personal or union emails for general practitioners who practised health care in Colombia in March 2020. The form was designed in Google Forms@, an application to conduct surveys and acquire opinion-based statistics, currently frequently used, easy to fill out and with the opportunity of virtuality. Participants were asked to apply the responses to the period between March 24 and 30, 2020, in phase one of mandatory confinement decreed by the Colombian government.

\section{Statistical Analysis}

Confirmatory factor analysis (CFA) was carried out to corroborate the onedimensional structure of the FCV-19S. Robust diagonally weighted least squares (RDWLS) was the extraction method, with a tetrachoric correlation matrix for factor extraction; this method was designed explicitly for ordinal data ( $\mathrm{Li} 2016$ ). It was estimated RMVA (robust mean and variance-adjusted (chi-square, df and $p$ ), RMSEA (root mean square error of approximation), CFI (comparative fit index), TLI (TuckerLewis index), SRMR (standardised mean square residual) and WRMR (weighted root mean square residual). 
Internal consistency was estimated with the Kuder-Richardson coefficient; it is indicated for dichotomous variables (Kuder and Richardson 1937) that is equivalent to Cronbach's alpha (Cronbach 1951). Moreover, McDonald's omega, $\Omega$, is a better measure of internal consistency when the principle of tau equivalence is assumed, assumed for the calculation of $\alpha$, it is that is, a vast difference it is observed among loadings of the items (McDonald 1970). For the items, the mean (M), standard deviation (SD), corrected Pearson's correlation between an item and total score, and Kuder-Richardson coefficient with the omission of the item was observed. CFA was performed in factor analysis programme (Lorenzo-Seva and Ferrando 2020), and internal consistency was computed in the Jamovi version 1.2.27.0 (Jamovi Project 2020).

\section{Results}

CFA showed the following goodness of fit coefficients for FCV-19S: RMVA chi-square = $39.29(\mathrm{df}=14, p=.0001)$, RMSEA $=0.06$ (90\% CI 0.05-0.08), CFI $=0.97$, TLI $=0.98$, $\mathrm{SRMR}=0.08$ and WRMR $=0.05$. After deleting items 3 (losing my life) and 7 (my heart races), FCV-19S-5 goodness of fit coefficients were RMVA chi-square $=7.54$ ( $\mathrm{df}=5, p=$ $0.18)$, RMSEA $=0.03(90 \%$ CI $0.01-0.05)$, CFI $=0.99$, TLI $=0.99$, SRMR $=0.02$ and WRMR $=0.03$.

Regarding internal consistency, the FCV-19S showed Kuder-Richardson coefficient $=0.16$ and $\Omega=0.42$. The FCV-19S-5 showed the Kuder-Richardson coefficient 0.67 and $\Omega=0.68$. Table 2 shows for FCV-19S-5, mean, standard deviation, corrected correlation of the item and the total score and the Kuder-Richardson coefficient if the item were omitted.

\section{Discussion}

In the present study, the FCV-19S presented low internal consistency and poor factor structure in Colombian physicians. A five-item version (FCV-19S-5) showed acceptable internal consistency and dimensionality.

These findings differ from the performance shown in the original FCV-19S study (Ahorsu et al. 2020). Similarly, they diverge from previous research carried out in the general population, whose internal consistencies ranged from 0.83 to 0.88 (Alyami et al. 2020; Haktanir et al. 2020; Perz et al. 2020; Sakib et al. 2020; Satici et al. 2020; Soraci et al. 2020; Tzur Bitan et al. 2020; Winter et al. 2020).

Table 2 Mean, standard deviation, corrected correlation between item and total score and Kuder-Richardson's coefficient if the item is omitted of the FCV-19S-5

\begin{tabular}{lllll}
\hline Item & Mean & SD & CC & Kuder-Richardson's coefficient ${ }^{1}$ \\
\hline 1. Afraid & 0.82 & 0.38 & 0.23 & 0.69 \\
2. Think about & 0.79 & 0.41 & 0.37 & 0.64 \\
4. Losing my life & 0.71 & 0.45 & 0.56 & 0.55 \\
5. Nervous or anxious & 0.67 & 0.47 & 0.59 & 0.53 \\
6. Sleep & 0.54 & 0.50 & 0.37 & 0.64 \\
\hline
\end{tabular}

${ }^{1}$ If the item is omitted 
The FCV-19-S data did not adjust for the one-dimensional structure, possibly the negative factor loads for items 3 and 7 (Bornovalova et al. 2020; Streiner 1994). These items had shown the lowest indicators in the Arabic (Alyami et al. 2020) and Israeli (Tzur Bitan et al. 2020) versions; however, it was not considered that there were sufficient criteria to consider it a separate factor (Alyami et al. 2020). Some authors disagree with retaining a factor with only two items because it is unlikely that fewer than three items can capture the complexity of a dimension (Gorsuch 1997; Streiner 1994).

The FVC-19S-5, with the elimination of items 3 and 7, showed a one-dimensional structure with high internal consistency. This finding shows the need to corroborate the performance of these versions in other Spanish speaker participants (Keszei et al. 2010; Sánchez and Echeverry 2004).

The findings of the present study suggest that the Colombian medical population should use the FCV-19S-5 as an instrument for measuring fear of COVID-19, instead of the original FCV-19S. However, it is necessary to corroborate this performance in other samples of Spanish speakers. The variations found between different populations suggest the need to permanently review the psychometric properties of health measurement instruments (CampoArias et al. 2012; Keszei et al. 2010).

The current study presents the performance of the Spanish version of the FVC-19-S and FVC-19S-5, which included a more conserved measurement of internal consistency, McDonald's omega (1970), and dichotomous answer options that can facilitate the process of completing the questionnaire. However, online survey research has some disadvantages such as uncertainty about data validity and sampling problems, for instance, self-selection bias and concerns around the design (Wright 2005). Likewise, the study has the limitations of validation studies that prevent the generalisation of results (Keszei et al. 2010). Moreover, no differential patterns of answered were explored for items that need to be checked (Yüksel et al. 2019).

It is concluded that the Spanish version of the FCV-19S presents a poor psychometric performance in Colombian physicians. The FCV-19S-5 shows better dimensionality and consistency indicators than the original seven-item version. These findings need to be corroborated in other samples of Spanish speakers.

Acknowledgments University of Cartagena and University of Magdalena supported the research.

\section{Compliance with Ethical Standards}

Conflict of Interest The authors declare that they have no conflict of interest.

\section{References}

Ahorsu, D. K., Lin, C. Y., Imani, V., Saffari, M., Griffiths, M. D., \& Pakpour, A. H. (2020). The fear of COVID19 scale: development and initial validation. International Journal of Mental Health and Addiction. https:// doi.org/10.1007/s11469-020-00270-8.

Alyami, M., Henning, M., Krägeloh, C. U., \& Alyami, H. (2020). Psychometric evaluation of the Arabic version of the fear of COVID-19 scale. International Journal of Mental Health and Addiction. https://doi.org/10. 1007/s11469-020-00316-X.

Barnette, J. J. (2000). Effects of stem and Likert response option reversals on survey internal consistency: if you feel the need, there is a better alternative to using those negatively worded stems. Educational and Psychological Measurement, 60(3), 361-370. https://doi.org/10.1177/00131640021970592. 
Bornovalova, M. A., Choate, A. M., Fatimah, H., Petersen, K. J., \& Wiernik, B. M. (2020). Appropriate use of bifactor analysis in psychopathology research: appreciating benefits and limitations. Biological Psychiatry, 88, 17-27. https://doi.org/10.1016/j.biopsych.2020.01.013.

Campo-Arias, A., Herazo, E., \& Oviedo, H. C. (2012). Factor analysis: fundamentals for the evaluation of measurement instruments in mental health. Revista Colombiana de Psiquiatría, 41(3), 659-671.

Colizzi, M., Bortoletto, R., Silvestri, M., Mondini, F., Puttini, E., Cainelli, C., et al. (2020). Medically unexplained symptoms in the times of Covid-19 pandemic: a case report. Brain, Behavior and Immunology, 100073. https://doi.org/10.1016/j.bbih.2020.100073.

Colombian National Health Institute. (2020). COVID-19 in Colombia. Report 21-09-2020 5:00pm. Retrieved from https://www.ins.gov.co/Noticias/paginas/coronavirus.aspx. Accessed 21 Sept 2020.

Cronbach, L. J. (1951). Coefficient alpha and the internal structure of tests. Psychometrika, 16(3), $297-334$. https://doi.org/10.1007/bf02310555.

Gorsuch, R. L. (1997). Exploratory factor analysis: its role in item analysis. Journal of Personality Assessment, 68(3), 532-560. https://doi.org/10.1207/s15327752jpa6803_5.

Guimaraes, M. B., Haas, V. J., Spadoti, R. A., Marques dos Santos, M., \& Galvão, C. M. (2017). Cultural adaptation and validation of an instrument on barriers for the use of research results. Revista LatinoAmericana da Enfermagem, 25, e.2852. https://doi.org/10.1590/15q8-8345.1652.2852.

Haktanir, A., Seki, T., \& Dilmac, B. (2020). Adaptation and evaluation of Turkish version of the fear of COVID19 scale. Death Studies, 1-9. https://doi.org/10.1080/07481187.2020.1773026.

Instituto Cervantes. (2018). Spanish: a living language. 2018 report. https://cvc.cervantes.es/lengua/espanol lengua_viva/pdf/espanol_lengua_viva_2018.pdf. Accessed 15 Sept 2020.

Jamovi Project. (2020). Jamovi. (Version 1.2) [Computer Software]. Retrieved from https://www.jamovi.org.

Keszei, A. P., Novak, M., \& Streiner, D. L. (2010). Introduction to health measurement scales. Journal of Psychosomatic Research, 68(4), 319-323. https://doi.org/10.1016/j.jpsychores.2010.01.006.

Knipe, D., Evans, H., Marchant, A., Gunnell, D., \& John, A. (2020). Mapping population mental health concerns related to COVID-19 and the consequences of physical distancing: a Google trends analysis. Wellcome Open Research, 5, 82-92. https://doi.org/10.12688/wellcomeopenres.15870.1.

Kuder, G. F., \& Richardson, M. W. (1937). The theory of the estimation of test reliability. Psychometrika, 2(3), 151-160. https://doi.org/10.1007/BF02288391.

Lai, J., Ma, S., Wang, Y., Cai, Z., Hu, J., Wei, N., Wu, J., du, H., Chen, T., Li, R., Tan, H., Kang, L., Yao, L., Huang, M., Wang, H., Wang, G., Liu, Z., \& Hu, S. (2020). Factors associated with mental health outcomes among health care workers exposed to coronavirus disease 2019. JAMA Network Open, 3(3), e203976. https://doi.org/10.1001/jamanetworkopen.2020.3976.

Li, C. H. (2016). Confirmatory factor analysis with ordinal data: Comparing robust maximum likelihood and diagonally weighted least squares. Behavior Research Methods, 48(3), 936-949. https://doi.org/10.3758/ s13428-015-0619-7.

Lin, C.-Y. (2020). Social reaction toward the 2019 novel coronavirus (COVID-19). Social Health and Behavior, 3(1), 1. https://doi.org/10.4103/shb.shb_11_20.

López, J. A. (2005). Politomous vs dichotomous items: a methodological study. Anales de Psicología, 21(2), 339-344 https://revistas.um.es/analesps/article/view/26941.

Lorenzo-Seva, U., \& Ferrando, P. J. (2020). Factor analysis (statistical program): Tarragona: Rovira i Virgili University. http://psico.fcep.urv.es/utilitats/factor/Bibliography.html. Accessed 1 Sept 2020.

Lu, W., Wang, H., Lin, Y., \& Li, L. (2020). Psychological status of medical workforce during the COVID-19 pandemic: a cross-sectional study. Psychiatry Research, 288, 112936. https://doi.org/10.1016/j.psychres. 2020.112936.

MacCallum, R. C., Widaman, K. F., Zhang, S., \& Hong, S. (1999). Sample size in factor analysis. Psychological Methods, 4(1), 84-99. https://doi.org/10.1037/1082-989X.4.1.84.

McDonald, R. P. (1970). The theoretical foundations of principal factor analysis, canonical factor analysis, and alpha factor analysis. British Journal of Mathematical and Statistical Psychology, 23(1), 1-21. https://oi. org/10.1111/j.2044-8317.1970.tb00432.x.

Nabi, R. L., \& Myrick, J. G. (2019). Uplifting fear appeals: considering the role of hope in fear-based persuasive messages. Health Communication, 34(4), 463-474. https://doi.org/10.1080/10410236.2017.1422847.

Pedrozo-Pupo, J., Pedrozo-Cortés, M., \& Campo-Arias, A. (2020). Perceived stress related to coronavirus disease (COVID-19) epidemic in Colombia: an online survey. Cadernos de Saúde Pública, 36(5), e00090520. https://doi.org/10.1590/0102-311x00090520.

Perz, C., Lang, B., \& Harrington, R. (2020). Validation of the fear of COVID-19 scale in a US College sample. International Journal of Mental Health and Addiction, 15, 1-11. https://doi.org/10.1007/s11469-020-00356-3.

Qiu, J., Shen, B., Zhao, M., Wang, Z., Xie, B., \& Xu, Y. (2020). A nationwide survey of psychological distress among Chinese people in the COVID-19 epidemic: implications and policy recommendations. General Psychiatry, 33(2), e100213. https://doi.org/10.1136/gpsych-2020-100213. 
Resolution 8490 from Health Ministry of Colombia. Bogota: Health Ministry of Colombia; 1993. https:/www. minsalud.gov.co/sites/rid/Lists/BibliotecaDigital/RIDE/DE/DIJ/RESOLUCION-8430-DE-1993.PDF.

Reznik, A., Gritsenko, V., Konstantinov, V., Khamenka, N., \& Isralowitz, R. (2020). COVID-19 fear in Eastern Europe: validation of the fear of COVID-19 scale. International Journal of Mental Health and Addiction. https://doi.org/10.1007/s11469-020-00283-3.

Sakib, N., Bhuiyan, A. K. M. I., Hossain, S., Al Mamun, F., Hosen, I., Abdullah, A. H., et al. (2020). Psychometric validation of the Bangla Fear of COVID-19 Scale: confirmatory factor analysis and Rasch analysis. International Journal of Mental Health and Addiction. https://doi.org/10.1007/s11469-020-00289-x.

Sánchez, R., \& Echeverry, J. (2004). Validating scales used for measuring factors in medicine. Revista de salud pública., 6(3), 302-318 http://www.scielo.org.co/scielo.php?script=sci_arttext\&pid=S0124$00642004000300006 \& \operatorname{lng}=$ en\&tlng=.

Satici, B., Saricali, M., Satici, S. A., \& Griffiths, M. D. (2020). Intolerance of uncertainty and mental wellbeing: serial mediation by rumination and fear of COVID-19. International Journal of Mental Health and Addiction. https://doi.org/10.1007/s11469-020-00305-0.

Soraci, P., Ferrari, A., Abbiati, F. A., Del Fante, E., De Pace, R., Urso, A., et al. (2020). Validation and psychometric evaluation of the Italian version of the Fear of COVID-19 Scale. International Journal of Mental Health and Addiction. https://doi.org/10.1007/s11469-020-00277-1.

Streiner, D. L. (1994). Figuring out factors: the use and misuse of factor analysis. The Canadian Journal of Psychiatry, 39(3), 135-140. https://doi.org/10.1177/070674379403900303.

Tzur Bitan, D., Grossman-Giron, A., Bloch, Y., Mayer, Y., Shiffman, N., \& Mendlovic, S. (2020). Fear of COVID-19 scale: psychometric characteristics, reliability and validity in the Israeli population. Psychiatry Research, 289, 113100. https://doi.org/10.1016/j.psychres.2020.113100.

Van Bavel, J. J., Baicker, K., Boggio, P. S., Capraro, V., Cichocka, A., Cikara, M., et al. (2020). Using social and behavioural science to support COVID-19 pandemic response. Nature Human Behaviour, 4, 1-12. https:// doi.org/10.1038/s41562-020-0884-z.

Weems, G. H., Onwuegbuzie, A. J., \& Lustig, D. (2003). Profiles of respondents who respond inconsistently to positively- and negatively-worded items on rating scales. Evaluation \& Research in Education, 17(1), 4560. https://doi.org/10.1080/14664200308668290.

Winter, T., Riordan, B., Pakpour, A., Griffiths, M., Mason, A., Poulgrain, J., et al. (2020). Evaluation of the English version of the Fear of COVID-19 Scale and its relationship with behavior change and political beliefs. International Journal of Mental Health and Addiction, 15, 1-11. https://doi.org/10.1007/s11469020-00342-9.

Witte, K., \& Allen, M. (2000). A meta-analysis of fear appeals: implications for effective public health campaigns. Health Education \& Behavior, 27(5), 591-615. https://doi.org/10.1177/109019810002700506.

World Health Organization. (2020). Novel Coronavirus (2019-nCoV) technical guidance. https:/www.who.int/ emergencies/diseases/novel-coronavirus-2019/technical-guidance. Accessed 6 June 2020.

World Medical Association. (2018). WMA declaration of Helsinki - ethical principles for medical research involving human subjects. The World Medical Association. https://www.wma.net/policies-post/wmadeclaration-of-helsinki-ethical-principles-for-medical-research-involving-human-subjects/.

Wright, K. B. (2005). Researching Internet-based populations: advantages and disadvantages of online survey research, online questionnaire authoring software packages, and web survey services. Journal of ComputerMediated Communication, 10(3), 1034. https://doi.org/10.1111/j.1083-6101.2005.tb00259.x.

Yüksel, S., Demir, P., \& Alkan, A. (2019). Factors causing occurrence of artificial dif: a simulation study for dichotomous data. Communications in Statistics: Simulation and Computation, 48(7), 2004-2011. https:// doi.org/10.1080/03610918.2018.1429622.

Publisher's Note Springer Nature remains neutral with regard to jurisdictional claims in published maps and institutional affiliations. 